\title{
The Psychological Effects of Exergames for Children and Adolescents with Obesity: A Systematic Review and Meta-Analysis
}

\author{
Alexandro Andrade, PhD, Clara Knierim Correia, MS, and Danilo Reis Coimbra, PhD
}

\begin{abstract}
The systematic review and meta-analysis were conducted to analyze the psychological effects of exergames for children and adolescents with overweight or obesity. In August 2018, the electronic databases searched were PubMed, Scopus, Web of Science, SPORTDiscus, Science Direct, CINAHL, and PsycINFO. The eligibility criteria were defined according to the population, intervention, comparison, outcome, and study design. In relation to the population, only studies with children or adolescents with overweight or obesity and without any other comorbidities were analyzed. Only publications in English were considered. Nine studies were selected. The comparisons identified were in relation to weight, type of activity, and play style versus control and preintervention. The magnitude of effect size suggests that the practice of exergaming has a small effect on psychological outcomes. Furthermore, cooperative games produced greater attraction to the game $(g=4.71$, 95\% confidence interval $[\mathrm{CI}]=3.23-6.19)$ and greater intrinsic motivation $(g=5.29 ; 95 \% \mathrm{CI}=3.68-6.90)$. It was verified that self-esteem (standard mean difference $[\mathrm{SMD}]=0.37 ; 95 \% \mathrm{CI}=0.09-0.66$ ), and self-efficacy $(\mathrm{SMD}=0.42 ; 95 \% \mathrm{CI}=0.06-0.79)$ improved after playing an exergame. This systematic review and metaanalysis suggest that exergames may be effective in improving psychological aspects of children and adolescents with overweight or obesity. Given the limited number of studies, it is essential to increase scientific research in this area.
\end{abstract}

Keywords: self-esteem, self-efficacy, depression, young

\section{Introduction}

O BESITY IS ASSOCIATED with reduced quality of life and deleterious health effects, including cancers and digestive diseases, and contributes to high morbidity and mortality. ${ }^{1,2}$ It presents as characteristic excess body fat and the World Health Organization defined obesity as a body mass index (BMI) $\geq 30 \mathrm{~kg} / \mathrm{m}^{2}$. Owing to the worldwide increase in the prevalence of obesity among children and adolescents, it is considered a public health issue. ${ }^{3}$ Adolescence is a period marked by the low physical activity and there is a positive relationship between greater time dedicated to sedentary behavior, especially owing to the hours spent in front of televisions, electronic games, and computers, and reducing outdoor activities, contributing to weight gain and overweight or obesity. ${ }^{4-6}$

Although the emotional etiology of obesity is still unclear, several rooted negative psychological aspects have been observed. ${ }^{7}$ Children and adolescents with overweight or obesity presented higher levels of depression, ${ }^{8}$ lower levels of self-efficacy, self-esteem, and higher body dissatisfaction than children and adolescents with normal weight. ${ }^{9-11}$ In this sense, the practice of physical exercise may reduce these deleterious effects associated with overweight or obesity in adolescence. $^{12,13}$

Exergaming or active video gaming refers to the new class of video games that allows the body to control the game, and requires gross motor movement. The players interact with the game through whole body movements and this improves energy expenditure. ${ }^{14,15}$ It requires the practitioner to perform body movements to participate in virtual sports, fitness exercises, or other interactive activities, unlike sedentary video games. Potentially, it improves levels of physical activity and achieves enough level of energy expenditure, reducing the boredom of repeated physical movements through increasing enjoyment and improving the adherence. ${ }^{16-22}$

Laboratory of Psychology of Sport and Exercise, Department of Physical Education, Center of Health Sciences and Sports, Santa Catarina State University, Florianópolis, Brazil. 
Therefore, it is believed that exergaming may be a positive strategy to promote changes in sedentary behavior of children and adolescents with overweight or obesity. ${ }^{23}$

Studies involving exergames have grown significantly in the last decade. ${ }^{24-27}$ Systematic reviews of the effects of exergames have focused on the physiological or health aspects of children and adolescents ${ }^{28-37}$ in a specific population. ${ }^{20}$ However, with regard to the psychological benefits for children and adolescents with overweight or obesity, research is still scarce. In this sense, it is important to summarize and analyze what these studies indicate about the psychological effects of exergaming for this population. Thus, the objective of the study was to verify the psychological effects of exergames for children and adolescents with overweight or obesity through a systematic review and meta-analysis of experimental studies. To the best of our knowledge, this is the first study that summarizes and performs a meta-analysis specifically on psychological effects of exergames on children and adolescents with overweight or obesity.

\section{Methods}

\section{Search strategy}

This review was conducted according to the PRISMA recommendations statement. ${ }^{38}$ In August 2018, the electronic databases searched were PubMed, Scopus, Web of Science, SPORTDiscus, Science Direct, CINAHL, and PsycINFO. The search strategy was: \#1 Exergames: exergames OR exergaming OR "active video game" OR "active videogaming," OR xavix OR XBOX OR "dance dance revolution" OR DDR OR wii; \#2 Adolescent: adolescent OR teenager OR young OR child*; \#3 Obesity: obesity OR overweight; Combination: \#1 AND \#2 AND \#3. Words searched were of the title, abstract, or subject. A manual search for potential studies was performed by examining the references of other relevant systematic reviews. Two reviewers independently conducted searches (D.R.C. and C.K.C.).

\section{Eligibility criteria}

Eligibility criteria were defined according to PICOS (Population, Intervention, Comparison, Outcome, and Study Design). Only studies with children or adolescents (up to 19 years), with obesity ( $z$ score $>+2$ and/or percentiles $>90$ th) or overweight $(z$ score $>+1$ and/or percentiles $>75$ th), and without any other comorbidities (diabetes or coronary artery disease) were analyzed. Interventions with exergames (Xbox, Wii, Dance Dance Revolution, etc.) were eligible, in which the participants were allocated to a group with exergames and compared with postintervention or control groups. Outcomes were analyzed in relation to the psychological aspects evaluated through scales or questionnaires. Studies not available in full, case studies, cross-sectional studies, theses, and conference articles were excluded. All the selected studies were peer-reviewed.

\section{Selection of studies}

The entire article selection process was performed independently by two researchers (D.R.C. and C.K.C.), based on the established eligibility criteria. In case of disagreement
(@20 percent), a third researcher was consulted (A.A.). In the first step, the titles of the records found were analyzed, after excluding the duplicates. In the second step, those considered relevant were evaluated by reading the abstract. Subsequently the article was analyzed in full and selected based on the eligibility criteria.

\section{Extraction of data}

Data extraction and synthesis were performed by analyzing the characteristics of the participants (sample, sex, age group, and BMI), the instrument used to evaluate the psychological outcome and the experimental protocol (intervention time, weekly frequency, number of sessions, duration, console, and intervention site).

Regarding the psychological effects of exergames, first, the results of the studies were organized into categories: positive effects, no effect, and negative effects. Subsequently, the mean and standard deviation (SD) data of the psychological outcomes of each of the groups at the pre- and postintervention moments, and the type of comparisons performed, were extracted and filed in an Excel spreadsheet.

\section{Assessment of study quality and risk of bias}

Analysis of study quality and risk of bias were assessed using the scale to analyze interventions with exergames. ${ }^{28}$ The authors proposed a scale of 10 items, evaluating different criteria: (1) randomization, (2) comparison with control group, (3) intervention with exergames only, (4) outcome assessed before and after intervention, (5) withdrawals reported and no more than 30, (6) groups are comparable at baseline on key outcome variables through statistical analyses, (7) data analyses were conducted while considering missing data, (8) analysis of the power of the sample was conducted to determine the appropriate size of the sample, (9) reliability and validity of the measurements were provided, and (10) followup, for at least 6 months after the intervention. Each item was classified as positive, negative, or not applicable (unknown or unreported). A quality index of the design ranging from 0 to 10 points was calculated by the sum of the positive items. The quality of the study was defined as high when the score reached a value $>5.5 .^{28}$

\section{Statistical analyses}

The data extracted from the different comparisons of each study were converted to a standard format, calculating effect size (ES) and confidence interval $(95 \% \mathrm{CI})$, applying the Hedges [Hedges's $g=(\mathrm{M} 1-\mathrm{M} 2) /(S D$ pooled $)$ ]. The ES (Hedges' $g$ ) for each study reflects the difference in outcome between intervention and control treatments, or between preand post-test conditions. The ES magnitude was categorized based on the Cohen classification ${ }^{39}$ : adverse effect $(\mathrm{ES}<0)$, no effect (ES: 0.0-0.1), small effect (ES: 0.1-0.5), intermediate effect (ES: 0.5-0.8), and large effect (ES $>0.8$ ). Statistical analyses were conducted using the Excel spreadsheet, based on the recommended calculations. ${ }^{40}$

Meta-analysis was performed on outcomes that were evaluated in more than one study, with similar types of comparisons. The results are presented in standard mean difference (SMD) when different instruments were used to establish the same outcome measure. SDs and 95\% CI for 
overall treatment effects were calculated. The following procedures were used for achieving the outcomes and possible comparisons for the meta-analysis: random effects and the inverse of the SMD variance. Heterogeneity was quantified using the Cochrane $Q$ test and the Higgins $I^{2}$. A value above $75 \%$ indicates high heterogeneity. Subgroup analyses were conducted for the psychological outcomes investigated, with the studies pooled according to the potential moderators found. Grouping was performed when the same psychological outcome was investigated with similar type of comparison in the studies. Forest Plots were developed using Review Manager 5.3 (Nordic Cochrane, Denmark). The definition of "level of evidence" was based on the Cochrane. $^{41}$

\section{Results}

\section{Description of studies included in the review}

Following the search, 1,580 records were identified. After selecting the records by reading the titles and excluding the duplicates, 101 articles were selected for reading the abstracts. In this stage, 71 records were excluded, leaving 30 records as potentially relevant by the eligibility criteria. After analyzing the articles in full, nine studies were included for the analysis (Fig. 1).

Participants and instruments. The 9 studies examined psychological aspects in 336 children and adolescents (53 percent girls), with a sample ranging from 13 to 54 participants (Table 1). The ages ranged from 6 to 19 years, and 3 studies were conducted with children and adolescents (6-16 years), whereas the others only investigated adolescents (12-19 years). Regarding the BMI of the nine studies selected, six reported in percentiles or $z$ scores. ${ }^{42,43}$ Various instruments had been used. The Childhood Depression Inventory was used in two studies. ${ }^{26,44}$

Interventions. Regarding the characteristics of the interventions, we observed differences between the studies (Table 2). Regarding the comparisons made in the selected studies, the categories identified were in relation to weight (comparison of adolescents with overweight or obesity and normal weight), the type of activity performed, and the style of play (cooperative versus competitive). Three studies compared exergames with control groups ${ }^{27,42,43}$ and six studies compared the preintervention moment with the postintervention moment. ${ }^{26,27,42-45}$

The intervention period varied from studies that used $1^{16,46}$ to 100 sessions. ${ }^{42,47}$ Thus, the protocol was categorized into short (interventions with up to 10 sessions) and long (interventions with 24 sessions or more).

The type of console for the practice of exergames was analyzed. ${ }^{20}$ It was observed that the Nintendo Wii ${ }^{\circledR}$ was used in five studies. ${ }^{16,42,44,45,47}$ In one study, the interventions took place with eight different consoles: DDR, Exerbike XG, Nintendo Wii, Makoto Interactive Arena, Lightspace Play Floor, Cybex Bring, Treadwall, and Xavix System. ${ }^{26}$ Only one study did not report the console model. ${ }^{44}$
FIG. 1. Study flow diagram.
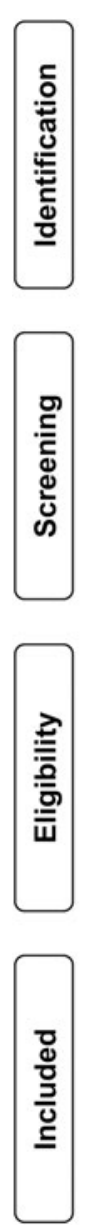

Records identified through database searching $(n=1580)$
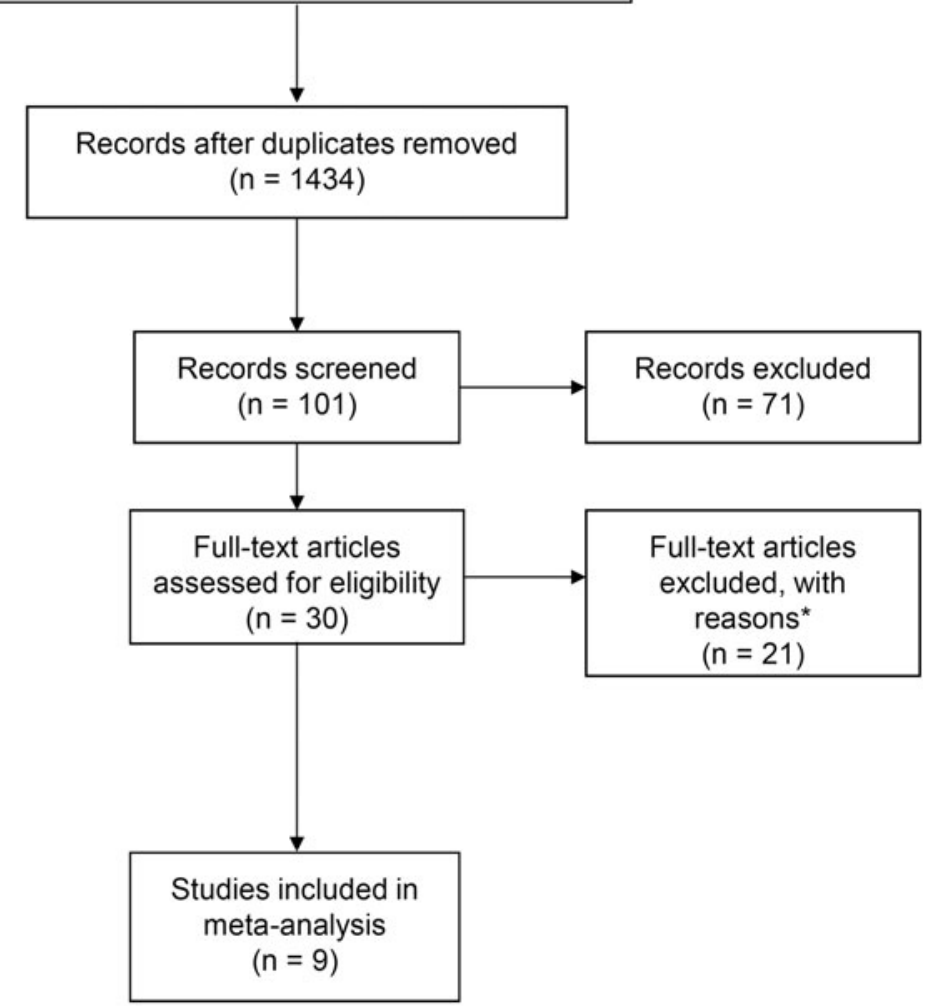
Table 1. Characteristics of the Participants and Measurement Used to Evaluate the Psychological OutComes of the Studies INCLUded IN THE REvieW

\begin{tabular}{|c|c|c|c|c|c|}
\hline Reference & $\begin{array}{l}\text { Participants } \\
\text { (boys/girls) }\end{array}$ & Age range & $B M I$ & Measurement & Outcome \\
\hline \multirow[t]{2}{*}{ Duman et al. ${ }^{44}$} & \multirow[t]{2}{*}{$50(21 / 29)$} & \multirow[t]{2}{*}{$12.16( \pm 0.99)$} & \multirow[t]{2}{*}{-} & $\begin{array}{l}\text { 1. Childhood Depression } \\
\text { Inventory }\end{array}$ & 1. Depression \\
\hline & & & & 2. The Piers-Harris Scale & $\begin{array}{l}\text { 2. Self-concept (self- } \\
\text { esteem) }\end{array}$ \\
\hline Santos et al. ${ }^{45}$ & $\begin{array}{l}42 \text { (not } \\
\text { informed) }\end{array}$ & $06-12$ & - & 1. Exercise Self-Efficacy & 1. Self-efficacy \\
\hline \multirow[t]{2}{*}{ Staiano et al. ${ }^{43}$} & \multirow[t]{2}{*}{37 girls } & \multirow[t]{2}{*}{$14-18$} & \multirow[t]{2}{*}{$2.2( \pm 0.5)^{\mathrm{a}}$} & $\begin{array}{l}\text { 1. Self-Efficacy for } \\
\text { Healthy Eating and } \\
\text { Physical Activity } \\
\text { Measure }\end{array}$ & 1. Self-efficacy \\
\hline & & & & $\begin{array}{l}\text { 2. Intrinsic Motivation } \\
\text { Inventory }\end{array}$ & 2. Intrinsic motivation \\
\hline Cebolla et al. ${ }^{16}$ & $21(8 / 13)$ & $06-16$ & $2.3( \pm 0.5)^{\mathrm{a}}$ & $\begin{array}{l}\text { 1. Self-Efficacy, Positive } \\
\text { Expectations and } \\
\text { Satisfaction }\end{array}$ & $\begin{array}{l}\text { 1. Self-efficacy, positive } \\
\text { expectations, } \\
\text { satisfaction }\end{array}$ \\
\hline \multirow[t]{3}{*}{ Staiano et al. ${ }^{46}$} & \multirow[t]{3}{*}{$54(24 / 30)$} & \multirow[t]{3}{*}{$15-19$} & \multirow[t]{3}{*}{-} & $\begin{array}{l}\text { 1. Exercise Confidence } \\
\text { Survey }\end{array}$ & 1. Self-efficacy \\
\hline & & & & $\begin{array}{l}\text { 2. Rosemberg Self-Esteem } \\
\text { Scale }\end{array}$ & 2. Self-esteem \\
\hline & & & & $\begin{array}{l}\text { 3. Friendship Quality } \\
\text { Questionnaire }\end{array}$ & 3. Peer support \\
\hline \multirow[t]{2}{*}{$\begin{array}{l}\text { Christison } \\
\text { and Khan }\end{array}$} & \multirow[t]{2}{*}{$48(26 / 22)$} & \multirow[t]{2}{*}{ 08-16 } & $2.24( \pm 0.41)^{\mathrm{a}}$ & $\begin{array}{l}\text { 1. Childhood Depression } \\
\text { Inventory }\end{array}$ & 1. Depression \\
\hline & & & $31.07( \pm 6.41)$ & $\begin{array}{l}\text { 2. Self-perception Profile } \\
\text { for Children }\end{array}$ & $\begin{array}{l}\text { 2. Self-worth (self- } \\
\text { esteem), social } \\
\text { acceptance, athletic } \\
\text { competence, physical } \\
\text { competence, } \\
\text { behavioral conduct }\end{array}$ \\
\hline \multirow[t]{2}{*}{ Staiano et al. ${ }^{42}$} & \multirow[t]{2}{*}{$31(16 / 15)$} & \multirow[t]{2}{*}{$15-19$} & \multirow[t]{2}{*}{$>75 \mathrm{th}^{\mathrm{b}}$} & $\begin{array}{l}\text { 1. Exergame Play } \\
\text { Inventory }\end{array}$ & 1. Intrinsic motivation \\
\hline & & & & $\begin{array}{l}\text { 2. Psychological } \\
\text { Attractiveness Scale }\end{array}$ & $\begin{array}{l}\text { 2. Psychological } \\
\text { attraction to exergame }\end{array}$ \\
\hline \multirow[t]{2}{*}{ Wagener et al. ${ }^{27}$} & \multirow[t]{2}{*}{$40(13 / 27)$} & \multirow[t]{2}{*}{$12-18$} & \multirow[t]{2}{*}{$3.15( \pm 0.19)^{\mathrm{a}}$} & $\begin{array}{l}\text { 1. The Perceived } \\
\text { Competence Scale }\end{array}$ & 1. Perceived competence \\
\hline & & & & $\begin{array}{l}\text { 2. The Behavior } \\
\text { Assessment System for } \\
\text { Children-2 }\end{array}$ & $\begin{array}{l}\text { 2. Anxiety, self-esteem, } \\
\text { depression, social } \\
\text { stress, relationship } \\
\text { with parents, } \\
\text { interpersonal relations, } \\
\text { internalizing and } \\
\text { externalizing } \\
\text { composite }\end{array}$ \\
\hline $\begin{array}{l}\text { Penko and } \\
\text { Barkley }{ }^{47}\end{array}$ & $13(8 / 5)$ & $8-12$ & $\begin{array}{l}\text { Boys: } 92.3( \pm 4.3)^{\mathrm{b}} \\
\text { Girls: } 95.4( \pm 3.6)^{\mathrm{b}}\end{array}$ & $\begin{array}{l}\text { 1. The Liking Analog } \\
\text { Scale }\end{array}$ & $\begin{array}{l}\text { 1. Liking (to enjoy the } \\
\text { exergame) }\end{array}$ \\
\hline
\end{tabular}

Values are given as mean (standard deviation).

${ }^{\mathrm{a} B M I} z$-score.

${ }^{b}$ BMI percent.

The place where the intervention occurred was also extracted for comparison. ${ }^{28}$ Two studies carried out the intervention in school ${ }^{46}$ and one in a community center. ${ }^{26}$ The remaining six studies were carried out in laboratories or at the at the university where the research was carried out.

Study quality. In the quality evaluation of the studies, the minimum score was fixed at 3 and the maximum at 7 . Six of the nine studies received a score above the median of 5.5 (Table 3) and were therefore considered to be of high methodological quality. ${ }^{28}$ The limitation common to all studies was related to criterion eight (analysis of sample power). All studies provided the reliability and validity of the measures used.

Summarization of the results. The psychological effects of exergames on children and adolescents with overweight or obesity were mainly self-efficacy $(n=4)$, self-esteem $(n=3)$, and depression $(n=3)$. In total, 19 different psychological outcomes were investigated in the studies (Table 4).

All the studies verified at least one psychological outcome with positive effects. Five studies had neutral effects 
Table 2. Characteristics of the Experimental Protocols of the Studies Included in the Review

\begin{tabular}{|c|c|c|c|c|c|}
\hline Reference & Groups & Comparisons & Protocol & Console & Local \\
\hline Duman et al. $^{44}$ & EG: only exergames & Pre $\times$ post & $\begin{array}{l}\text { Long: } 24 \text { sessions } \\
3 \times \text { per week for } 8 \\
\text { weeks } \\
\text { Duration: } 45 \text { minutes }\end{array}$ & $\begin{array}{l}\text { Not } \\
\text { Informed }\end{array}$ & Laboratory \\
\hline Santos et al. ${ }^{45}$ & EG: only exergames & $\begin{array}{l}\text { Weight } \\
\text { Pre } \times \text { post }\end{array}$ & $\begin{array}{l}\text { Long: } 49 \text { sessions } \\
7 \times \text { per week for } 7 \\
\text { weeks } \\
\text { Duration: } 45 \text { minutes }\end{array}$ & $W i i$ & Laboratory \\
\hline Staiano et al. ${ }^{43}$ & $\begin{array}{l}\text { EG: only exergames } \\
\text { CG: control }\end{array}$ & $\begin{array}{l}\text { Exergames } \times \text { control } \\
\text { Pre } \times \text { post }\end{array}$ & $\begin{array}{l}\text { Long: } 36 \text { sessions } \\
3 \times \text { per week for } 12 \\
\text { weeks } \\
\text { Duration: } 60 \text { minutes }\end{array}$ & Xbox & Laboratory \\
\hline \multirow[t]{2}{*}{ Cebolla et al. ${ }^{16}$} & $\begin{array}{l}\text { EG: walking on the } \\
\text { treadmill with the } \\
\text { support of the video } \\
\text { game platform }\end{array}$ & Weight & Short: A session & $W i i$ & Laboratory \\
\hline & $\begin{array}{l}\text { CG: walking on the } \\
\text { treadmill }\end{array}$ & Activity & $\begin{array}{l}\text { Duration: } 8 \text { minutes } \\
\text { ( } 4 \text { minutes long at a } \\
\text { fixed speed with } 4 \\
\text { minutes additional } \\
\text { increasing speed) }\end{array}$ & & \\
\hline \multirow[t]{3}{*}{ Staiano et al. ${ }^{46}$} & $\begin{array}{l}\text { EG1: cooperative } \\
\text { games }\end{array}$ & Game style & Long: 100 sessions & $W i i$ & School \\
\hline & $\begin{array}{l}\text { EG2: competitive } \\
\text { games }\end{array}$ & Exergames $\times$ control & $\begin{array}{l}5 \times \text { week, at lunchtime } \\
\text { or after school, for } 20 \\
\text { weeks }\end{array}$ & & \\
\hline & CG: control & Pre $\times$ post & $\begin{array}{l}\text { Duration: } 30 \text { minutes. } \\
\text { (lunch time) }+60 \\
\text { minutes (after } \\
\text { school) }\end{array}$ & & \\
\hline $\begin{array}{l}\text { Christison } \\
\quad \text { and } \operatorname{Khan}^{26}\end{array}$ & $\begin{array}{l}\text { EG: exergame }+ \\
\text { physical activity }\end{array}$ & Pre $\times$ post & $\begin{array}{l}\text { Short: } 10 \text { sessions } \\
1 \times \text { week, for } 10 \text { weeks } \\
5 \text { sessions: exergame }+5 \\
\text { sessions only: } \\
\text { exergame with } \\
\text { physical activity } \\
\text { Duration: } 60 \text { minutes }\end{array}$ & Several & $\begin{array}{l}\text { Community } \\
\text { Center }\end{array}$ \\
\hline \multirow[t]{2}{*}{ Staiano et al. $^{42}$} & $\begin{array}{l}\text { EG1: cooperative } \\
\text { games }\end{array}$ & Game style & Long: 100 sessions & Wii & School \\
\hline & $\begin{array}{l}\text { EG2: competitive } \\
\text { games }\end{array}$ & & $\begin{array}{l}5 \times \text { week, at lunchtime } \\
\text { and after school, for } \\
20 \text { weeks } \\
\text { Duration: } 30 \text { minutes } \\
\text { (lunch time) }+60 \\
\text { minutes (after } \\
\text { school) }\end{array}$ & & \\
\hline \multirow[t]{2}{*}{ Wagener et al. ${ }^{27}$} & $\begin{array}{l}\text { EG: exergame }+ \\
\text { walking on the } \\
\text { treadmill }\end{array}$ & Exergames $\times$ control & Long: 30 sessions & $\begin{array}{l}\text { Dance } \\
\quad \text { Revolution }\end{array}$ & Laboratory \\
\hline & CG: Control & Pre $\times$ post & $\begin{array}{l}3 \times \text { week, for } 10 \text { weeks } \\
\text { Duration: } 75 \text { minutes } \\
\quad(4 \text { sets of } 15 \text { minutes } \\
\quad+5 \text { minutes rest } \\
\text { between sets) }\end{array}$ & & \\
\hline Penko and Barkley ${ }^{47}$ & $\begin{array}{l}\text { EG1: boys } \\
\text { EG2: girls }\end{array}$ & Activity & $\begin{array}{l}\text { Short: A session } \\
\text { Duration: } 90 \text { minutes } \\
\text { (4 conditions of } 10 \\
\text { minutes: rest, } \\
\text { walking, sedentary } \\
\text { game and exergame) }\end{array}$ & Wii & Laboratory \\
\hline
\end{tabular}




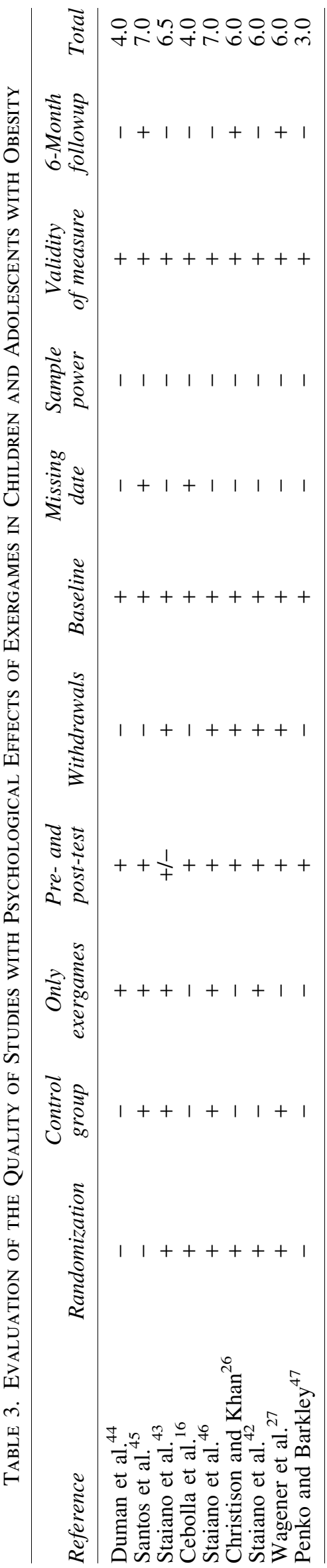

(without significant difference) on the psychological outcomes investigated. No studies reported negative psychological effects of exergames on children and adolescents.

No difference in the attraction of the game and intrinsic motivation when the participants played in the competitive mode, verified positive effect only in the cooperative mode. ${ }^{26}$ With regard to self-esteem and self-efficacy, the results were divergent. Self-esteem had positive effects. ${ }^{26}$ However, in other studies these effects were neutral. ${ }^{27,46}$ In self-efficacy, three studies ${ }^{43,45,46}$ verified positive effects, whereas one study the effects were neutral. ${ }^{16}$ In one study, self-efficacy was positive only in cooperative mode. ${ }^{46}$

Effect size. The ES of the studies ranged from -0.37 ( $95 \% \mathrm{CI}=-1.04$ to 0.29 ) in the game style comparison with the self-efficacy outcome ${ }^{44}$ to $5.29(95 \% \mathrm{CI}=3.68$ to 6.91$)$ in the game style comparison with the self-esteem outcome. ${ }^{40}$ With regard to the magnitude of the ESs (Fig. 2), it was observed that, in general, there was a small effect (36 percent) for most comparisons with psychological outcomes. In the comparison between types of activities, 60 percent had a great effect. In the comparison between normal weight, the majority presented intermediate magnitude (67 percent). In the exergames versus control comparison, 40 percent presented intermediate effect, whereas between game styles, 50 percent had no effect (50 percent).

Of the 9 studies included in this systematic review and meta-analysis, 13 different psychological outcomes were investigated once by category. Therefore, in these results, limited evidence should be considered in the question about the hypothesis that the practice of exergames produces positive psychological effects on children and adolescents with overweight or obesity.

Children and adolescents with overweight or obesity experienced greater satisfaction when engaging with exergames $(\mathrm{ES}=0.79 ; 95 \% \mathrm{CI}=0.16-1.42)$ compared with children and adolescents of a normal weight. Children and adolescents with overweight or obesity reported higher satisfaction $(\mathrm{ES}=0.87 ; 95 \% \quad \mathrm{CI}=0.24-1.51)$, self-efficacy $(\mathrm{ES}=0.71 ; 95 \% \mathrm{CI}=0.09-1.34)$, and positive expectations $(\mathrm{ES}=1.41 ; 95 \% \mathrm{CI}=0.73-2.09)$ compared with those who practiced sedentary video games or walking.

Comparing competitive games with cooperatives, children and adolescents with overweight or obesity felt more attraction to the game $(\mathrm{ES}=4.71 ; 95 \% \mathrm{CI}=3.23-6.19)$ and greater intrinsic motivation $(\mathrm{ES}=5.29 ; 95 \% \mathrm{CI}=3.68-6.90)$ when playing cooperative games.

Comparing the practice of exergames with control, children and adolescents showed improvement in the relationship with parents $(\mathrm{ES}=0.83 ; 95 \% \mathrm{CI}=0.17-1.50)$ and in the perception of competence (ES I $=0.71 ; 95 \% \mathrm{CI}=0.06-1.37$ ).

Meta-analyses. Meta-analysis was possible in the selfefficacy, self-esteem, and depression (in the preintervention comparison), self-esteem and self-efficacy (compared with the control group), and dislike (in comparison with other activities) outcomes. Each analysis included between two and four studies. Moderate evidence indicated that there was no difference in the effect of exergames on the self-efficacy of children and adolescents with overweight or obesity (Fig. 3), comparing the pre-postintervention moment $\left(I^{2}=0\right.$ percent, $p=0.96)$ with a small combined SMD $(0.27,95 \%$ 
Table 4. Summarization of the Effects of Psychological Outcomes Investigated by Comparison OF INCLUDED STUDIES

\begin{tabular}{|c|c|c|c|c|c|c|c|c|c|c|}
\hline \multirow{2}{*}{$\begin{array}{l}\text { Mental } \\
\text { health } \\
\text { outcome }\end{array}$} & \multicolumn{5}{|c|}{$\begin{array}{l}\text { Positive } \\
\text { effect }\end{array}$} & \multicolumn{5}{|c|}{$\begin{array}{l}\text { Not } \\
\text { effect }\end{array}$} \\
\hline & Weight & Activity & $\begin{array}{l}\text { Game } \\
\text { style }\end{array}$ & $\begin{array}{c}\text { vs. } \\
\text { Control }\end{array}$ & Pre $\times$ post & Weight & Activity & $\begin{array}{l}\text { Game } \\
\text { style }\end{array}$ & $\begin{array}{c}\text { vs. } \\
\text { Control }\end{array}$ & Pre $\times$ post \\
\hline Anxiety & & & & & & & & & VIII & VIII \\
\hline Athletic competence & & & & & $\mathrm{I}, \mathrm{VI}$ & & & & & VI \\
\hline Attraction to exergame & & & VII & & & & & VII & & \\
\hline $\begin{array}{l}\text { Behavioral conduct } \\
\text { Depression }\end{array}$ & & & & & VI & & & & & \\
\hline $\begin{array}{l}\text { Depression } \\
\text { Enjoy the practice } \\
\text { of exergames }\end{array}$ & & IX & & & I & & & & VIII & VI, VIII \\
\hline Exposure of symptoms & & & & VIII & VIII & & & & & \\
\hline Interpersonal relationships & & & & & & & & & VIII & VIII \\
\hline Intrinsic motivation & & & VII & III & III & & & VII & & \\
\hline Peer support & & & V & V & $\mathrm{V}$ & & & & & \\
\hline Perception of competence & & & & VIII & VIII & & & & & \\
\hline $\begin{array}{l}\text { Perception of social } \\
\text { acceptance }\end{array}$ & & & & & & & & & & VI \\
\hline Physical appearance & & & & & & & & & & VI \\
\hline Positive expectations & IV & IV & & & & & & & & \\
\hline $\begin{array}{l}\text { Relations with parents } \\
\text { Satisfaction }\end{array}$ & IV & IV & & & & & & & & \\
\hline Self esteem & & & & & & & & $\mathrm{V}$ & V, VIII & V, VIII \\
\hline $\begin{array}{l}\text { Self-efficacy } \\
\text { Social stress }\end{array}$ & II & & $\mathrm{V}$ & III, V & II, III, V & IV & IV & & & VIII \\
\hline
\end{tabular}

I-Duman et al. ${ }^{44}$; II-Santos et al. ${ }^{45}$; III-Staiano et al. ${ }^{43}$; IV-Cebolla et al. ${ }^{16}$; V—Staiano et al. ${ }^{42}$; VI-Christison and Khan ${ }^{26}$; VIIStaiano et al. ${ }^{42}$; VIII-Wagener et al. ${ }^{27}$; IX-Penko and Barkley ${ }^{47}$.

FIG. 2. Magnitude of the effect of exergames on psychological aspects in children and adolescents with overweight or obesity.
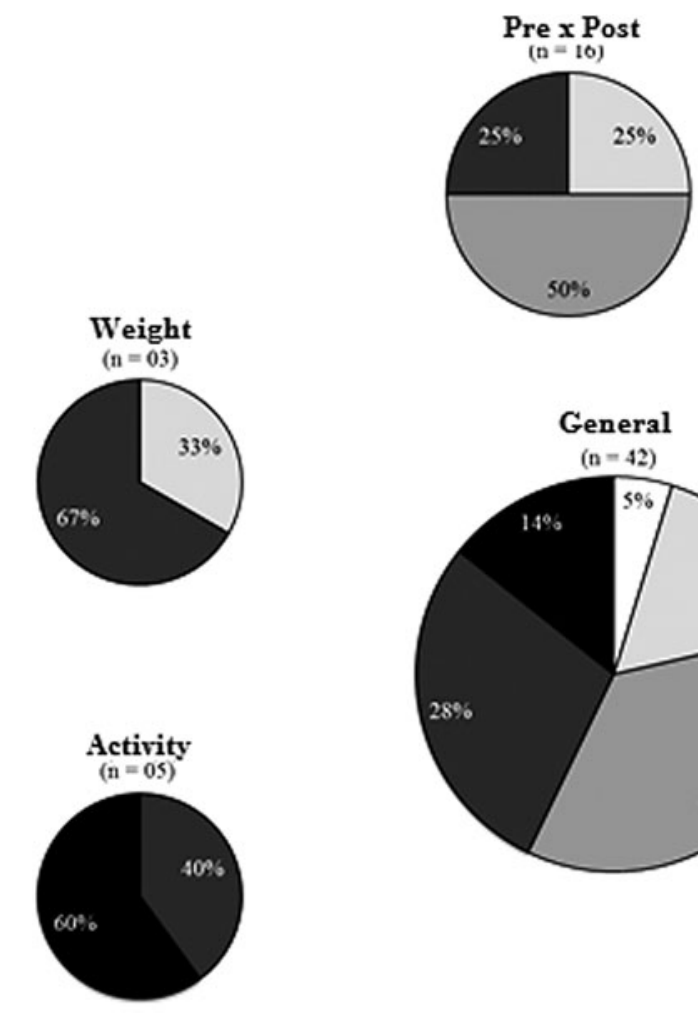

$\square$ Adverse Effect

$\square$ No Effect

$\square$ Small Effect

- Intermediate Effect

- Large Effect
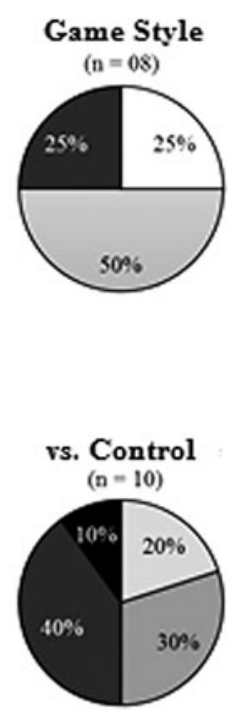


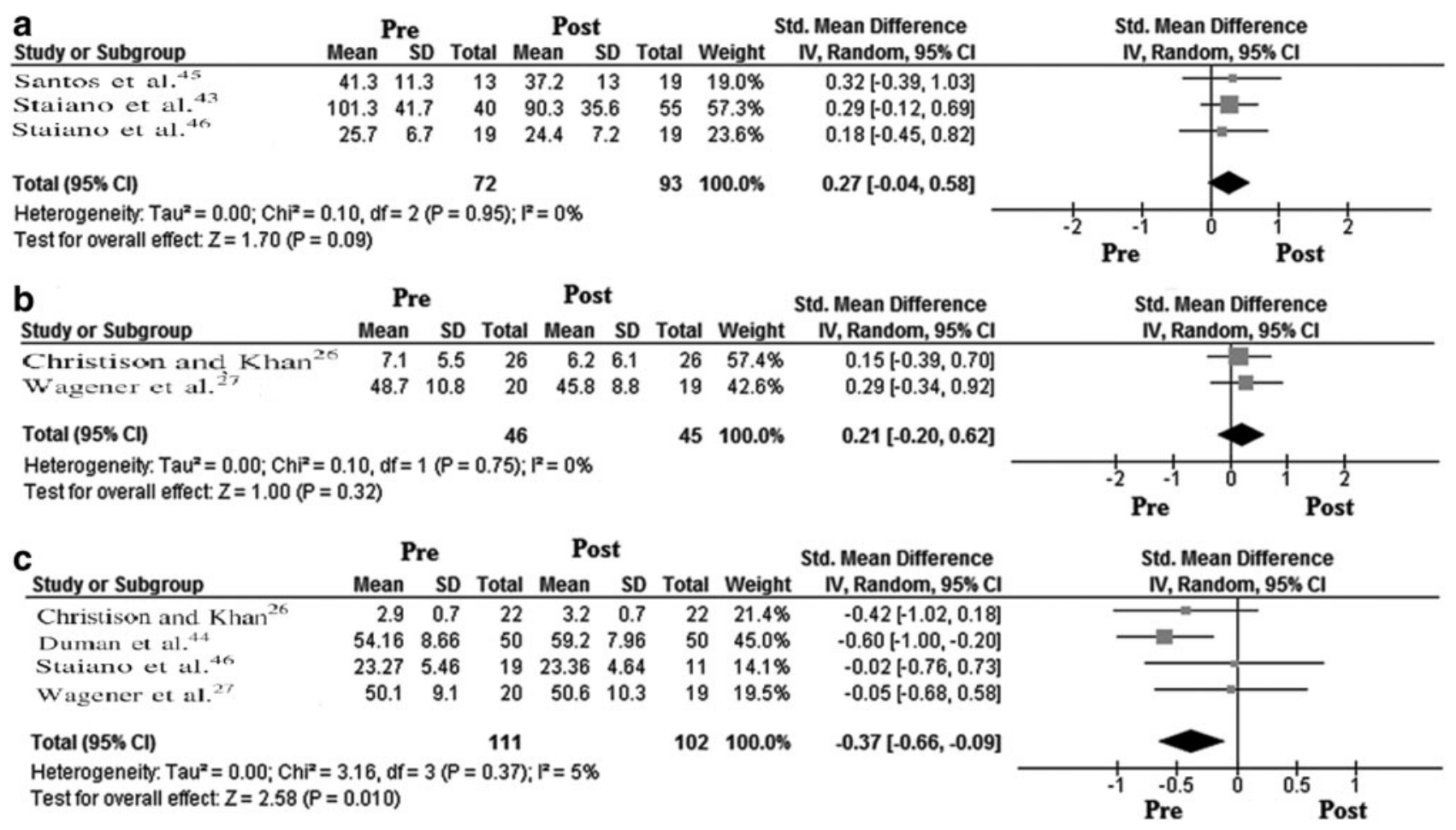

FIG. 3. Effect of exergames on the self-efficacy (a), depression (b), and self-esteem (c) of children and adolescents with overweight or obesity. CI, confidence interval; $S D$, standard deviation.

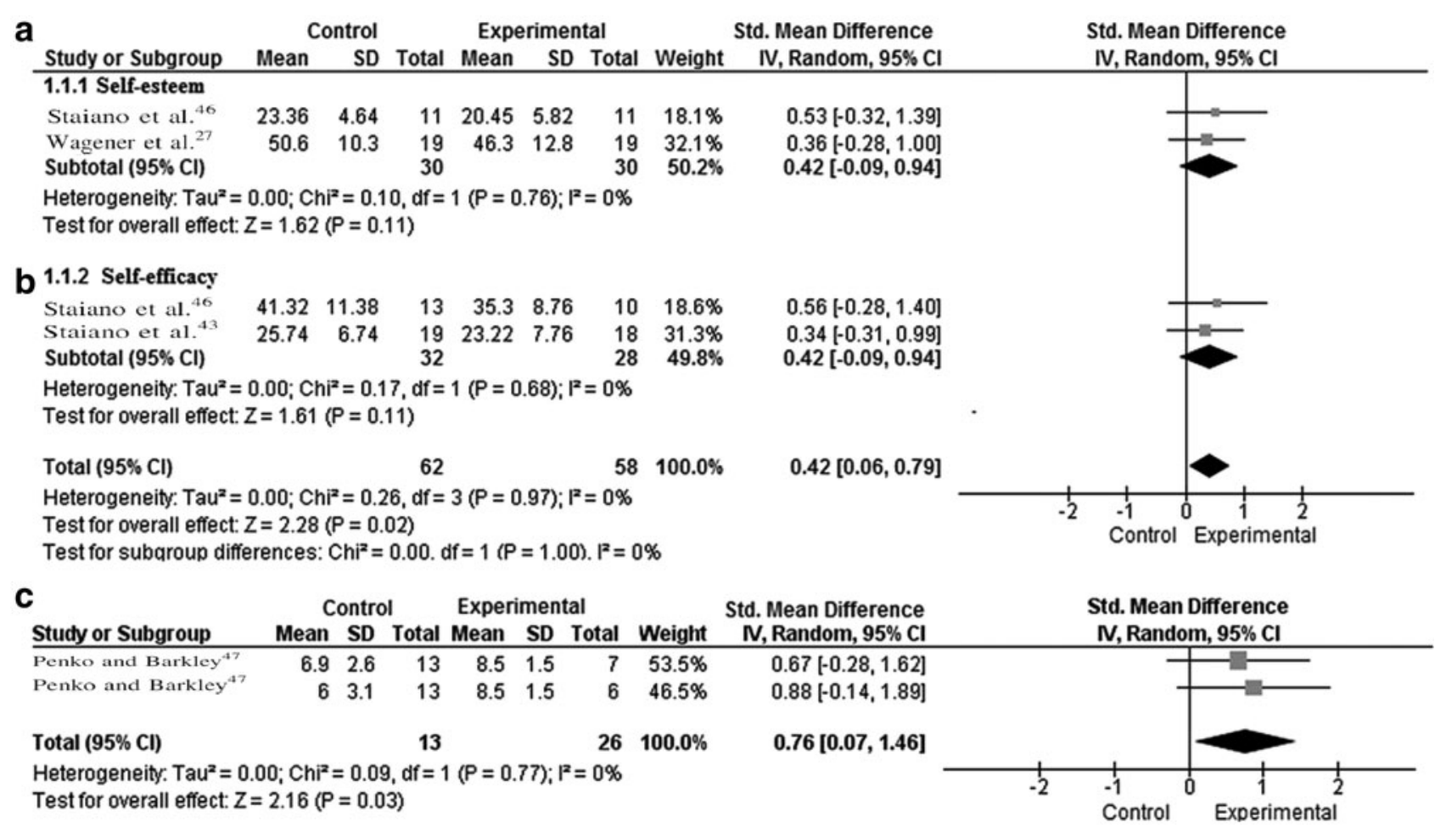

FIG. 4. Effect of exergames compared with control on the self-esteem (a), self-efficacy (b), and liking the activity (c) in children and adolescents with overweight or obesity. 
$\mathrm{CI}=-0.04$ to 0.58$)$. Moderate evidence indicated that there was no difference in the effect of exergames on the depression of children and adolescents with overweight or obesity (Fig. 3), comparing the pre- and postintervention moments $\left(I^{2}=0\right.$ percent, $\left.p=0.75\right)$ with a small combined SMD $(0.21$; $95 \% \mathrm{CI}=-0.20$ to 0.62 ). Moderate evidence indicated that exergames improved the self-esteem of children and adolescents with overweight or obesity (Fig. 3), comparing the pre-postintervention time $\left(I^{2}=5\right.$ percent, $\left.p=0.37\right)$ with a small combined SMD ( $-0.37,95 \% \mathrm{CI}:-0.09$ to -0.66$)$.

Regarding the meta-analysis of the psychological effects of exergames in children and adolescents with overweight or obesity, the comparisons between exergames and control groups in postintervention are given in Figure 4. The combined analysis of the three studies showed moderate evidence of the effect $\left(I^{2}=0\right.$ percent, $\left.p=0.97\right)$, with a small combined SMD $(0.42,95 \%$ CI $=0.06-0.79)$. There was limited evidence of the effect of exergames on liking the activity (Fig. 4). Children and adolescents with overweight or obesity liked to practice exergames more than sedentary video games or walking $\left(I^{2}=0\right.$ percent, $\left.p=0.77\right)$, with an intermediate SMD $(0.76 ; 95 \% \mathrm{CI}=0.07-1.46)$.

\section{Discussion}

This systematic review and meta-analyses sought to synthesize the psychological effects of exergame in children and adolescents with overweight or obesity from the nine studies. The results of the meta-analysis indicated that after the practice of exergames there was an improvement in selfesteem and in comparison with the control group, there were improvements in self-esteem and self-efficacy. Compared with other activities, children and adolescents with overweight or obesity liked to practice exergames more than other activities. The results will be discussed by topics.

\section{Participants}

In total, 336 children and adolescents were investigated. Most of the studies investigated boys and girls of a wide age range, and details about the specific effects of gender or age group were not provided. Three studies did not provide details regarding the BMI of the sample, just mentioned that they are overweight or obese. Overweight and obesity among children and adolescents have been considered one of the most common health problems of the century, ${ }^{4}$ with expressive increase in the past decades. ${ }^{48}$ Therefore, despite the scarcity of studies that investigated the effect of exergames for children and adolescents with overweight or obesity, interventions using exergames have been recommended as additional strategies to increase the level of physical activity and energy expenditure of this population. ${ }^{20,22}$

\section{Psychological effects}

In total, 19 different psychological outcomes were investigated. Self-efficacy, self-esteem, and depression were the most commonly studied. Depression and low self-esteem are mental health comorbidities associated with overweight or obesity in children and adolescents, ${ }^{9,49}$ and self-efficacy is an important mediator of adherence to physical exercise. ${ }^{50}$ Selfefficacy can be developed through interventions, such as the practice of exergames. ${ }^{46}$ The perception of self-efficacy in the performance of a task is essential for maintaining and engaging in the practice of it. Thus, higher levels of selfefficacy result in greater adherence to exergame intervention programs, contributing to a more active lifestyle. ${ }^{20,51}$

\section{Differences between protocols}

The differences between the protocols limit the consensus about the effectiveness of exergames for the psychological effects in children and adolescents with overweight or obesity. The protocols ranged from 1 session, ${ }^{16}$ with no reported duration, performed in the laboratory, up to 100 sessions, for 10 weeks, with 90 minutes duration divided into two periods, and performed at school. ${ }^{46}$ Despite the lack of standardization the interventions that were performed in school settings or community center, three of the nine selected studies stands out. $^{26,42}$ The school has a fundamental role in the prevention and treatment of obesity, ${ }^{52}$ and studies carried out in familiar environments have practical implications of exergames for public health. ${ }^{28}$

\section{Study quality}

Six of the nine studies were considered of high quality. Despite this, the results should be analyzed with caution, because no study reported calculating the power of the sample and some studies reported withdrawals. Therefore, future research should investigate strategies to improve adherence to exergames interventions. ${ }^{53}$

\section{Summary of results}

In total, 19 psychological outcomes and 5 different types of comparison were investigated in the 9 studies. In general, the results are conflicting because of the different designs adopted in the studies. Nevertheless, despite the limited effects, we consider exergames as a potential intervention to reduce the sedentary behavior. ${ }^{54}$ To date, only one study has performed comparisons between exergames and other activities and reported more positive expectations and satisfaction when practicing exergames than when walking. Therefore, more studies are necessary.

\section{Psychological effects of exergames}

The results regarding the magnitude of ESs have shown that the practice of exergames has a small beneficial effect for children and adolescents on psychological outcomes. In the comparison between exergames and walking, the magnitude was large and intermediate, demonstrating that exergame produces better psychological benefits in children and adolescents with overweight or obesity than other selected activities. A comparison of cooperative games and competitive games indicated an adverse effect on selfefficacy: competitive games were more effective in improving self-efficacy than cooperative games.

Overweight children increased their self-confidence through greater mastery of skills, with a subsequent increase in motivation for exercise and greater adherence in exergame than normal exercise. ${ }^{45}$ Thus, exergaming is an important intervention to reduce the sedentary behavior. ${ }^{16,20,47}$ Children had more satisfaction and positive expectations when practicing exergames in conjunction with walking than just walking $^{16}$ and enjoyed exercising exergames more than 
walking or playing sedentary video games. ${ }^{47}$ Among game styles, it seems that cooperative games produce more positive effects on most psychological outcomes than competitive games. In addition, cooperative games promoted greater body weight loss in adolescents with overweight or obesity than competitive games. ${ }^{46}$ These results support the hypothesis that the practice of exergames by children and adolescents with overweight or obesity can increase adherence to physical practice. ${ }^{45,46}$

It was possible to develop the meta-analyses of the most investigated psychological outcomes (self-esteem, selfefficacy, and depression) besides enjoyment of the practice. After the intervention with exergames, there was an improvement in self-esteem. Low self-esteem in children and adolescents with overweight or obesity is usually conditioned by dissatisfaction with their body weight and perception of their body image as being far from the ideal. This in turn leads to eating disorders, a sedentary lifestyle in adult life. ${ }^{55,56}$ In this sense, the exergame practice had a positive aspect, although there was no difference in depression and self-efficacy. Our hypothesis is that exergames had an impact on self-esteem because it responds more acutely, compared with depression and self-efficacy, which require longer periods of intervention, to achieve important changes.

In comparison with the control group, there was improvement in self-esteem and self-efficacy. Finally, children and adolescents with overweight or obesity liked to practice exergames more than to practice other activities, compared with video games or walking.

Although evidence shows that interventions only with exergames are not enough to reduce the body weight of children and adolescents with overweight or obesity, ${ }^{57}$ these results in psychological outcomes are important, mainly to encourage interventions in more applied settings such as schools. The main recommendation to exergames for children and adolescents with overweight or obesity are the reduction of time spent engaged in sedentary behavior, the adoption of a more active lifestyle, and the transfer to the practice of physical exercise. ${ }^{43}$

This review was conducted in accordance with the recommended statement. ${ }^{38}$ However, the low number of studies included, the different comparisons, together with the variety of psychological outcomes investigated, limited the possibilities of further analysis in this study. Therefore, we must consider the interpretations of these results as a preliminary attempt of investigating the psychological effects of the practice of exergames on children and adolescents with overweight or obesity.

We can point out some limitations associated with this meta-analysis. The results demonstrated that sample size is still a limiting factor for generalizations of the results. Owing to the low number of studies investigating the practice of exergames by adolescents with overweight or obesity, the number of studies that analyzed the same psychological outcomes was limited. In addition, we limited our analysis to psychological outcomes. Thus, it remains inconclusive if the psychological effects, such as the changes in self-esteem and self-efficacy, are because of the reduction of body weight and/or improvement of cardiorespiratory fitness, for example. Therefore, according to the results, it is suggested that exergames should be used with the objective of reducing the time spent in sedentary behavior and to promote greater commitment to the practice of physical activity by children and adolescents with overweight or obesity. ${ }^{28,58}$ Despite the interest in using exergame over a longer period of time is low, ${ }^{59}$ exergames promote positive effects in psychological, especially in self-esteem and self-efficacy.

Future studies should be conducted with randomized controlled trials and with a larger number of participants. In addition, studies with more direct applications in practice, such as those conducted in the field (school based or in community centers) is required. Others psychological effects, as well as interventions of longer duration, to verify if the psychological effects can help in the maintaining the practice of physical exercise should be studied. Studies with followups to verify if the psychological effects persist after the intervention closes are also recommended.

\section{Conclusions}

This systematic review and meta-analysis provided a synthesis of the psychological effects of exergames in children and adolescents with overweight or obesity. We observed an increase in self-esteem after playing exergames, an improvement in self-esteem and self-efficacy compared with the control group, and that children liked to practice exergames more than other selected activities. Most comparisons produced a small ES. Finally, children and adolescents with overweight or obesity felt more satisfied when practicing exergames than adolescents with normal weight, and had greater self-efficacy, positive expectations, and satisfaction when practicing exergames than performing other selected activities. In general, owing to the fun, pleasure, joy, and innovative technology provided by exergames, they have the potential to attract children and adolescents who are overweight or obese.

\section{Author Disclosure Statement}

No competing financial interests exist.

\section{Funding Information}

This study was supported by the Research and Innovation Support Foundation of the State of Santa Catarina (FAPESC) through Project (grant numbers 2287, PAP 04/2014 and by the Coordenação de Aperfeiçoamento de Pessoal de Nível Superior-Brasil (CAPES)—Finance Code 001.

\section{References}

1. Ogden CL, Flegal KM. Changes in terminology for childhood overweight and obesity. National Health Statistics Reports 2010; 25:1-5.

2. Xu S, Xue Y. Pediatric obesity: causes, symptoms, prevention and treatment (review). Experimental and Therapeutic Medicine 2016; 11:15-20.

3. Yanovski JA. Pediatric obesity. An introduction. Appetite 2015; 93:3-12.

4. Thibault H, Contrand B, Saubusse E, et al. Risk factors for overweight and obesity in French adolescents: physical activity, sedentary behavior and parental characteristics. Nutrition 2010; 26:192-200.

5. Rossi CE, Albernaz DO, Vasconcelos AG, et al. Television influence on food intake and obesity in children and adolescents: a systematic review. Revista de Nutrição 2010; 23:607-620. 
6. Echeverria SE, Kang AL, Isasi CR, et al. A community survey on neighborhood violence, park use, and physical activity among urban youth. Journal of Physical Activity and Health 2014; 11:186-194.

7. Fernandes J, Ferreira-Santos F, Miller K, et al. Emotional processing in obesity: a systematic review and exploratory meta-analysis. Obesity Reviews 2018; 19:111-120.

8. Luppino FS, Wit LM, Bouvy PF, et al. Overweight, Obesity, and Depression. Archives of General Psychiatry 2010; 67:220.

9. Taylor A, Wilson C, Slater A, et al. Self-esteem and body dissatisfaction in young children: associations with weight and perceived parenting style. Clinical Psychologist 2012; 16:25-35.

10. Matias TS, Kieling M, Barros S, et al. Corporal satisfaction associated with physical activity practice during adolescence. Motriz 2010; 16:370-378.

11. Stewart JG, Esposito EC, Glenn CR, et al. Adolescent selfinjurers: comparing non-ideators, suicide ideators, and suicide attempters. Journal of Psychiatric Research 2017; 84:105-112.

12. Vargas IC, Sichieri R, Sandre-Pereira G, et al. Evaluation of an obesity prevention program in adolescents of public schools. Revista de Saude Publica 2011; 45:59-68.

13. Nobles J, Radley D, Dimitri P, et al. Psychosocial interventions in the treatment of severe adolescent obesity: the SHINE program. Journal of Adolescent Health 2016; 59: 523-529.

14. Staiano AE, Calvert SL. Exergames for physical education courses: physical, social, and cognitive benefits. Child Development Perspectives 2011; 5:93-98.

15. Bailey BW, Mcinnis K. Energy Cost of Exergaming: a comparison of the energy cost of 6 forms of exergaming. Arch Pediatr Adolesc Med 2011; 165:597-602.

16. Cebolla A, Álvarez-Pitti JC, Provinciale JG, et al. Alternative options for prescribing physical activity among obese children and adolescents: brisk walking supported by an exergaming platform. Nutricion Hospitalaria 2015; 31:841848.

17. Sun H. Impact of exergames on physical activity and motivation in elementary school students: a follow-up study. Journal of Sport and Health Science 2013; 2:138-145.

18. Gao Z, Podlog L, Huang C. Associations among children's situational motivation, physical activity participation, and enjoyment in an active dance video game. Journal of Sport and Health Science 2013; 2:122-128.

19. Maloney AE, Carter Bethea T, Kelsey KS, et al. A pilot of a video game (DDR) to promote physical activity and decrease sedentary screen time. Obesity 2008; 16:20742080.

20. Lee S, Kim W, Park T, et al. The psychological effects of playing exergames: a systematic review. Cyberpsychology, Behavior, and Social Networking 2017; 20:513-532.

21. Sween J, Wallington SF, Sheppard V, et al. The role of exergaming in improving physical activity: a review. Journal of Physical Activity and Health 2014; 11:864-870.

22. Mears BD, Hansen L. Technology in physical education active gaming: definitions, options and implementation. Strategies 2009; 23:26-29.

23. Eliacik K, Bolat N, Koçyiğit C, et al. Internet addiction, sleep and health-related life quality among obese individuals: a comparison study of the growing problems in adolescent health. Eating and Weight Disorders-Studies on Anorexia, Bulimia and Obesity 2016; 21:709-717.
24. Kharrazi H, Lu AS, Gharghabi F, et al. A scoping review of health game research: past, present, and future. Games for Health: Research, Development, and Clinical Application 2012; 1:153-164.

25. Andrade A, Correia CK., Cruz WMD, et al. Acute effect of exergames on children's mood states during physical education classes. Games for Health Journal 2019.

26. Christison A, Khan HA. Exergaming for health. Clinical Pediatrics 2012; 51:382-388.

27. Wagener TL, Fedele DA, Mignogna MR, et al. Psychological effects of dance-based group exergaming in obese adolescents. Pediatric Obesity 2012; 7:68-74.

28. Gao Z, Chen S. Are field-based exergames useful in preventing childhood obesity? A systematic review. Obesity Reviews 2014; 15:676-691.

29. Larsen LH, Schou L, Lund HH, et al. The physical effect of exergames in healthy elderly-a systematic review. Games for Health: Research, Development, and Clinical Application 2013; 2:205-212.

30. LeBlanc AG, Larouche R, Chaput J-P, et al. No clear evidence that exergames can prevent obesity. Obesity Reviews 2014; 15:692-693.

31. Liang Y, Lau PWC. Effects of active videogames on physical activity and related outcomes among healthy children: a systematic review. Games for Health: Research, Development, and Clinical Application 2014; 3:122-144.

32. Zeng N, Pope Z, Lee JE, et al. A systematic review of active video games on rehabilitative outcomes among older patients. Journal of Sport and Health Science 2017; 6: 33-43.

33. Zeng N, Pope Z, Lee JE, et al. The role of active video accompanied exercises in preventing obesity in children: a prospective study from Turkey. Clinical Pediatrics 2017; 6: $1-20$.

34. Bochner RE, Sorensen KM, Belamarich PF. The impact of active video gaming on weight in youth: a meta-analysis. Clinical Pediatrics 2015; 54:620-628.

35. Pope Z, Zeng N, Gao Z. The effects of active video games on patients' rehabilitative outcomes: a meta-analysis. Preventive Medicine 2017; 95:38-46.

36. Gao Z, Chen S, Pasco D, et al. A meta-analysis of active video games on health outcomes among children and adolescents. Obesity Reviews 2015; 16:783-794.

37. Li J, Theng Y-L, Foo S. Effect of exergames on depression: a systematic review and meta-analysis. Cyberpsychology, Behavior, and Social Networking 2016; 19:34-42.

38. Moher D, Shamseer L, Clarke M, et al. Preferred reporting items for systematic review and meta-analysis protocols (PRISMA-P) 2015 statement. Systematic Reviews 2015; 4: $1-9$.

39. Cohen J. (1988). The effect size index: $d$. Statistical power analysis for the behavioral sciences. Mahwah, NJ: Lawrence Erlbaum Associates, pp. 284-288.

40. Borenstein M, Hedges LV, Higgins JPT, et al. A basic introduction to fixed-effect and random-effects models for meta-analysis. Research Synthesis Methods 2010; 1:97-111.

41. van Tulder MW, Assendelft WJJ, Koes BW, et al. Method guidelines for systematic reviews in the cochrane collaboration back review group for spinal disorders. Spine 2003; 22:1290-1299.

42. Staiano AE, Abraham AA, Calvert SL. Motivating effects of cooperative exergame play for overweight and obese adolescents. Journal of Diabetes Science and Technology 2012; 6:812-819. 
43. Staiano AE, Beyl RA, Hsia DS, et al. Twelve weeks of dance exergaming in overweight and obese adolescent girls: transfer effects on physical activity, screen time, and self-efficacy. Journal of Sport and Health Science 2017; 6: 4-10.

44. Duman F, Kokacya MH, Dogru E, et al. The role of active video accompanied exercises in preventing obesity in children: a prospective study from Turkey. Journal of Clinical Research in Pediatric Endocrinology 2016; 8:334340.

45. Santos H, Bredehoft MD, Gonzalez FM, et al. Exercise video games and exercise self-efficacy in children. Global Pediatric Health 2016; 3:1-6.

46. Staiano AE, Abraham AA, Calvert SL. Adolescent exergame play for weight loss and psychosocial improvement: a controlled physical activity intervention. Obesity 2013; 21:598-601.

47. Penko AL, Barkley JE. Motivation and physiologic responses of playing a physically interactive video game relative to a sedentary alternative in children. Annals of Behavioral Medicine 2010; 39:162-169.

48. Han JC, Lawlor D, Kimm SYS. Childhood Obesity-2010: progress and Challenges. Lancet 2010; 375:1737-1748.

49. Rankin J, Matthews L, Cobley S, et al. Psychological consequences of childhood obesity: psychiatric comorbidity and prevention. Adolescent Health, Medicine and Therapeutics 2016; 7:125-146.

50. White K, Kendrick T, Yardley L. Change in self-esteem, self-efficacy and the mood dimensions of depression as potential mediators of the physical activity and depression relationship: exploring the temporal relation of change. Mental Health and Physical Activity 2009; 2: 44-52.

51. Robertson J, Jepson R, Macvean A, et al. Understanding the importance of context: a qualitative study of a locationbased exergame to enhance school childrens physical activity. PLoS One 2016; 11:1-27.

52. Jones RA, Lubans DR, Morgan PJ, et al. School-based obesity prevention interventions: practicalities and considerations. Obesity Research \& Clinical Practice 2014; 8: e497-e510.
53. Smart NA, Waldron M, Ismail $\mathrm{H}$, et al. Validation of a new tool for the assessment of study quality and reporting in exercise training studies: TESTEX. International Journal of Evidence-Based Healthcare 2015; 13:9-18.

54. Pate RR, Flynn JI, Dowda M. Policies for promotion of physical activity and prevention of obesity in adolescence. Journal of Exercise Science and Fitness 2016; 14:47-53.

55. Murray M, Dordevic AL, Bonham MP. Systematic review and meta-analysis: the impact of multicomponent weight management interventions on self-esteem in overweight and obese adolescents. Journal of Pediatric Psychology 2017; 42:379-394.

56. Liu M, Wu L, Ming Q. How does physical activity intervention improve self-esteem and self-concept in children and adolescents? Evidence from a meta-analysis. PLoS One 2015; 10:1-17.

57. Vasconcelos B, Formalioni A, Galliano L, et al. Comparison of physiological responses during practices of exergames and conventional activities: a systematic review and metaanalysis. Revista Brasileira de Atividade Física e Saúde 2017; 22:332-342.

58. Pereira JC, Rodrigues ME, Campos HO, et al. Exergames as an alternative to increased energy expenditure: a systematic review. Revista Brasileira de Atividade Física e Saúde 2012; 17:332-334.

59. Radon K, Fürbeck B, Thomas S, et al. Feasibility of activity-promoting video games among obese adolescents and young adults in a clinical setting. Journal of Science and Medicine in Sport 2011; 14:42-45.

Address correspondence to: Dr. Alexandro Andrade Laboratory of Psychology of Sport and Exercise Department of Physical Education Center of Health Sciences and Sports Santa Catarina State University Pascoal Simone, 358, Coqueiros CEP 88080-350 Florianópolis Brazil

E-mail: alexandro.andrade.phd@gmail.com 